\title{
Tecnologia e autogestão: um enfoque relacional
}

\author{
Technology and self-management: a relational approach
}

\author{
Marcos de Carvalho Dias \\ Henrique Viana Arce
}

\section{Resumo}

Os empreendimentos autogestionários têm representado, principalmente após a década de 90 , uma alternativa de trabalho e renda aos trabalhadores de empresas falidas em decorrência do processo de abertura comercial promovido pelo governo federal nesse período. Tais empreendimentos são assumidos pelos trabalhadores e assumidos de forma autogerida, em que as principais decisões em relação à forma de produção, e a propriedade dos meios de produção são coletivos e determinados democraticamente. Porém um dos principais aspectos destes empreendimentos se refere a forma de tecnologia utilizada durante o processo produtivo e que irá possibilitar sua viabilidade econômica e promover as condições e princípios estabelecidos pela produção autogestionária. Por isso, o objetivo deste texto é discutir a relação entre a produção organizada de forma coletiva e a tecnologia utilizada nesta forma de organização da produção, a partir dos principais enfoques e discussões propostos por diversos autores.

Palavras-chaves: tecnologia; autogestão; competitividade.

\begin{abstract}
The self-managing enterprises are represented, especially after the 90s, a source of employment and income to the employees of bankrupt as a result of the process of trade liberalization promoted by the federal government during this period. Such developments are made by workers in a self-managed and undertaken, in which major decisions regarding the form of production and ownership of the means of production are collective and democratically determined. But one of the main aspects of these enterprises refers to a form of technology used during the production process and will enable their economic viability and promote the conditions and principles established by self-managed production. Therefore, the objective of this paper is to discuss the relationship between the collectively organized production and technology used in this form of organization of production, from the main approaches and discussions proposed by several authors.
\end{abstract}

Keywords: technology, self-management, competitiveness.

\section{Introdução}

O modelo de desenvolvimento econômico brasileiro iniciado em meados da década de 90 , baseado principalmente na abertura comercial, elevada taxa de juros e valorização cambial, levaram à transformações na produção industrial, por meio de mudanças na forma de organização de produção que resultaram no aumento da qualidade dos produtos e na flexibilização da produção, e transformações no mercado de trabalho, por meio do aumento das exigências referentes às qualificações formal e técnica.

Tais transformações se deram por meio da adoção, pelas empresas brasileiras, de inovações tecnológicas, com a substituição de máquinas obsoletas por novas máquinas e equipamentos modernos, e inovações organizacionais, com a adoção de novos modelos de organização produtiva.

Um das consequências desse quadro foi a emergência de um conjunto de iniciativas próprias dos trabalhadores de fábricas falidas ou que estavam em desemprego há muito tempo, cujo objetivo era tentar se reinserir no mercado através de formas associativas de produção, resultando em várias empresas originárias da massa falida e em cooperativas dos diversos setores.

Esses empreendimentos surgem como conseqüência do esforço dos trabalhadores em reconquistar seus empregos, seja pela recolocação em funcionamento das empresas em que trabalhavam, seja pela criação de novas empresas. 
Como resultado observa-se nesse período o aumento da incidência das iniciativas dos trabalhadores de empresas falidas que passam a assumi-las de forma coletiva e democrática, compartilhando as principais decisões em relação aos objetivos e procedimentos a serem adotados na produção, como volume de produção, forma de atuação no mercado e tecnologia adotada.

Muitos destes empreendimentos tornam-se viáveis economicamente, mantendo-se no mercado de forma competitiva.

Considerando, portanto, a importância desses empreendimentos como alternativa viável de trabalho e renda para trabalhadores de empresas falidas, e a necessidade de se manterem no mercado de forma competitiva, convém discutir a relação entre os objetivos destes empreendimentos e a adequação da tecnologia adotada pelos mesmos, a partir da abordagem de diversos autores.

Nas pesquisas e discussões acadêmicas e científicas no Brasil que abordam tanto a tecnologia e suas variantes (inovação tecnológica, modernização, etc.) quanto a autogestão, é possível notar que tais abordagens não são relacionadas, e que os pesquisadores e atores dos dois universos quase não "dialogam" entre si. Nessas condições o resultado é a carência de pesquisas que reúnam os dois temas.

Sendo assim, o objetivo geral deste texto é unicamente discutir a relevância das abordagens sobre tecnologia para o estudo das iniciativas de organização da produção de forma coletiva, como a autogestão da produção. Para isso faremos, num primeiro momento, uma breve discussão sobre as abordagens sobre o conceito de tecnologia, seguido por uma apresentação sobre o conceito e as características da produção autogestionária de forma geral.

Na segunda e última parte realizaremos uma discussão a partir dos autores que debatem sobre a importância e as consequências da tecnologia para a produção coletiva, considerando o impacto do tipo de tecnologia adotada e forma de concepção desta, para a manutenção dos princípios da autogestão, enquanto um processo democrático e participativo, bem como a importância desta tecnologia para a autonomia dos trabalhadores associados.

\section{O conceito de tecnologia}

A abordagem sobre o conceito, natureza e implicações da tecnologia tem sido objeto de estudo de diversos autores em diversas áreas do conhecimento, sendo discutida a partir de sua importância econômica, política e social, bem como de suas implicações para a organização da produção.

Tal fato foi observado por Drucker (1973), ao apontar que os textos que tratavam da tecnologia reconheciam a complexidade e variedade dos elementos envolvidos na discussão, e que tais elementos influenciavam a formação da concepção de tecnologia, e também eram influenciados por ele: a economia, o sistema jurídico, o arranjo institucional e os valores morais, sociais, religiosos e científicos. Para esse autor, "[...] ninguém possui o conhecimento sobre todas as coisas, que variam constantemente, no entanto, todas estas coisas são incorporadas à tecnologia de uma forma ou de outra, de um ponto ou de outro" (p.157).

Essas diversas abordagens buscam discutir o papel da tecnologia no desenvolvimento econômico e sua relação com a realidade social, influenciando e sendo influenciada por esta mesma realidade.

O debate entre essas diversas abordagens é sintetizado por Dagnino (2008) em dois pólos principais: um deles considera que a tecnologia não exerce influência sobre a realidade social, e, portanto, o desenvolvimento tecnológico possui uma trajetória própria, avançando de forma contínua e linear (neutralidade da ciência e da tecnologia). O outro parte do pressuposto de que o desenvolvimento tecnológico é influenciado pela sociedade e, portanto, sua trajetória é socialmente determinada, controlada por grupos sociais, que a torna funcional em favor de seus interesses, inibindo as transformações sociais e condicionando o desenvolvimento econômico (determinismo tecnológico).

Porém, mesmo relevante para o entendimento do papel da ciência e da tecnologia no desenvolvimento econômico e social, convém ressaltar que não será discutido neste texto o caráter dialético da tecnologia, discussão esta já feita com propriedade na obra de Vieira Pinto (2005). Diferente disso, será abordado o caráter genérico da tecnologia e seu uso em formas alternativas de organização da produção, notadamente a produção autogestionária.

Considerando tal objetivo, o conceito de "tecnologia" é definido como um conjunto de instrumentos, métodos e meios utilizados na organização ou produção de determinado objeto a ser empregado em distintos modos de produção, sendo subdividido em duas dimensões: as tecnologias gerenciais, ligadas ao modo de organização da produção, e as tecnologias materiais, que se referem aos aparatos tecnológicos e aos processos de produção. O primeiro caso é representado pelas técnicas de gestão e modelos de organização da produção, e o segundo é representado pelas máquinas, equipamentos e ferramentas utilizados na realização do trabalho. 
Nesse sentido, a tecnologia corresponde a um conjunto integrado de conhecimentos, ferramentas, técnicas e procedimentos de trabalho que são aplicados no processo de produção de bens e serviços, e representa uma forma "[...] de intervir no curso das coisas, seja para impedir certos estados de se reproduzirem, seja, ao contrário, para fazer reaparecerem estados que não apareceriam espontaneamente" (LADRIĖRE, 1979, p.59).

De forma geral, ela representa um fator essencial na introdução de mudanças na forma de produção, por meio da junção entre pensar e agir, entre a teoria e a prática, e como a expressão do modo em que, num determinado momento, o homem estabelece relações com seu entorno e consigo mesmo.

Em razão disso, a tecnologia representa algo além das máquinas e equipamentos utilizados num sistema produtivo, ou conforme define Fleury (1990), um conjunto de informações variadas utilizadas na produção de bens e serviços, cuja origem e métodos de obtenção são diversos. Mais que isso, representa a combinação entre conhecimento humano, um sistema social e suas expectativas em relação ao resultado desejado desta combinação.

É desse processo que derivam a forma de organização e os instrumentos utilizados na realização da produção, cujo resultado será funcional ao contexto socioeconômico vigente e aos acordos sociais estabelecidos nesse contexto (GARCIA E VIÉITEZ, 1998).

Por isso, as considerações de Vieira Pinto (2005) sobre a o papel da tecnologia na constituição das relações humanas partem da correlação entre a tecnologia e a técnica, e ambas como resultado do comportamento natural do ser humano, do seu processo de constituição como ser social, e o que o distingue de outros seres da natureza.

Como técnica esse autor compreende não somente a produção de artefatos, aplicações de novas formas de operação ou ações humanas necessárias para o domínio da natureza (realtechnik), mas também uma forma de mediação entre a finalidade humana consciente, a natureza e a produção de bens e serviços.

Já o conceito de tecnologia é ampliado por esse autor como "[...] um conjunto de técnicas de que dispõe uma determinada sociedade, em qualquer fase histórica de seu desenvolvimento" (VIEIRA PINTO, 2005, p. 220) e, portanto, toda criação tecnológica, após ser aceita e reconhecida pela sociedade como tal, resulta numa profunda modificação nos hábitos sociais, nas formas de interrelacionamento e comunicação e na forma de pensar dos seres humanos.

\section{Autogestão da produção}

As iniciativas concretas do que passou a ser chamado de autogestão da produção, teve início a partir das ações dos trabalhadores no início dos anos 70 na França, com a retomada, por esses, de uma empresa produtora de relógios que se encontrava em estado falimentar. Em seguida são registradas ações, notadamente na Europa, dos trabalhadores de empresas falidas, no sentido de reassumirem a produção e a gerenciá-la de forma coletiva, além de ações de grupos sociais na criação de empreendimentos coletivos em que os trabalhadores eram os proprietários e os gerenciavam de forma coletiva (SINGER, 2002).

Tal forma de organização da produção passou a ser denominada de "autogestão" da produção, uma tradução literal da expressão servo-croata ("samo" sendo o equivalente eslavo do prefixo grego "auto", e "upravlje" significando aproximativamente "gestão"), devido à similaridade deste movimento com a forma de organização coletiva da produção implementada na ex-lugoslávia durante a década de 1950 (GUILLERM e BOURDET, 1976; ROSANVALLON, 1976).

No Brasil a ações em relação a tal forma de organização da produção, de maneira similar ao adotado na Europa, se destacam a partir da década e 80 e se intensificam na década de 90 , devido ao aumento do número de falências de empresas em decorrência das mudanças no padrão de concorrência interna, ou abertura comercial.

Quanto às características dessa forma de organização da produção, os empreendimentos autogestionários, como qualquer empreendimento de forma geral, estão integrados ao conjunto de relações de produção que determinam o modo de produção capitalista, por meio de sua inclusão na divisão social do trabalho e participação nos sistema de trocas.

Se caracterizam pela gestão de forma compartilhada e coletiva pelos trabalhadores que dele participam. Isto porque, neste caso, os trabalhadores são proprietários dos meios de produção, o que pressupõe a necessidade de um envolvimento pleno nas decisões relacionadas à produção.

Quanto aos aspectos organizacionais, autores como Liboni e Pereira (2002), Faria (2003) apontam algumas características que devem ser observadas neste tipo de empreendimento:

A propriedade coletiva dos meios de produção, ou seja, inexiste a figura legal de um indivíduo ou grupo de indivíduos que respondem pela posse das máquinas e equipamentos do empreendimento, que é feito por um conjunto de trabalhadores, por meio de seus representantes legais. 
Nesse mesmo sentido, a estrutura hierárquica destes empreendimentos caracteriza-se por ser verticalizada, com níveis de diferenciação entre funções reduzidas.

As funções de liderança são exercidas por meio da eleição direta dos membros, por um período determinado, e podendo ser destituída pelo grupo em casos pré-determinados por este. Isso permite a rotatividade e alternância das funções de execução e gerenciamento das atividades produtivas entres estes membros, pois a autoridade é representada e exercida de forma coletiva, por meio da liderança eleita e delegada temporariamente, devendo exercer as funções a partir das determinações estabelecidas pelo grupo.

Outra característica a ser observada nesses empreendimentos é a cooperação entre os diversos setores que compõem a produção, por meio do compartilhamento dos conhecimentos adquiridos e das situações vivenciadas durante a execução das atividades produtivas. Também ocorre por meio da participação direta e efetiva dos membros nas decisões relacionadas à produção a atribuição de forma homogênea das responsabilidades sobre o planejamento, organização, execução e obtenção de resultados desta.

\section{Tecnologia e autogestão}

Como abordado, a autogestão corresponde a uma forma de organização da produção baseada em outros elementos e objetivos que vão além da busca pela maximização do lucro, principal objetivo de uma empresa convencional.

Por esse motivo, a tecnologia, como variável estruturante do processo produtivo de qualquer forma de organização da produção, corresponde a um dos fatores essenciais para a viabilidade dos empreendimentos autogestionários.

Conforme Dagnino (2004), o que pode tornar a produção autogestionária viável não é somente a forma de organização da produção, mas sim a tecnologia utilizada no processo produtivo, não basta que o empreendimento seja dos cooperados e que adote a autogestão na produção. É necessário que a tecnologia utilizada também seja concebida de forma autogestionária, pelos agentes que dela irão fazer uso, como "[...] um processo desenvolvido no lugar onde essa tecnologia vai ser utilizada, pelos atores que irão utilizá-las" (p. 56).

Historicamente tal abordagem sobre a tecnologia a ser adotada pela produção autogestionária se assemelha à concepção teórica sobre o conceito de tecnologia adotada por diversos autores a partir da década de 70, com destaque para as abordagens de Schumacher (1979), cujo aspecto principal da discussão era a apropriação da utilização, nos países subdesenvolvidos, das tecnologias gestadas nos países desenvolvidos. Esse autor defendia a necessidade do desenvolvimento de uma tecnologia alternativa à tecnologia convencional, denominada de tecnologia intermediária, cuja concepção e resultado final (o artefato tecnológico ou o método de organização da produção) são baseados em soluções locais, derivadas das próprias demandas e necessidades das comunidades.

Ainda no propósito de discutir a necessidade de outra base técnica para a adoção da produção autogestionária, convém considerar igualmente a abordagem de Feenberg (2002) sobre o papel da tecnologia na forma de organização da produção.

Para esse autor, a consolidação de formas alternativas de produção (alternativas à produção capitalista), pressupõe como condição necessária (mas não suficiente), a constituição de outro conjunto de tecnologias, concebida por outros atores sociais. Ele parte do pressuposto de que não existe um padrão tecnológico definido, mas sim a construção local de uma tecnologia, baseada nas condições e especificidades da sociedade que a concebe e, portanto, esta tecnologia é gerada a partir deste contexto social específico.

Tal autor sugere a construção de uma nova base técnica que irá constituir um modelo de organização da produção alternativo (socialista, autogestionário ou outro) por meio de um processo democrático, em que a escolha do projeto tecnológico a ser implementado deve ser concebido a partir de dentro, ou seja, pelos atores que irão utilizá-lo.

Portanto, a escolha desse projeto tecnológico deve ocorrer de forma democrática, por meio da participação efetiva e direta destes atores de forma a interferir decisivamente na configuração desta tecnologia com o intuito de moldá-la aos seus objetivos e necessidades.

Convém ressaltar que esse autor não desconsidera o estágio atual do desenvolvimento científico e tecnológico, e as potencialidades da tecnologia convencional, não sendo necessário um retorno à Idade Média ou à tecnologia rudimentar, mas sim a elaboração de outra tecnologia que incorpore outras variáveis, como a participação dos trabalhadores na sua concepção e na sua utilização durante o processo de trabalho.

Considerando que essas são as abordagens teóricas que tratam dos aspectos tecnológicos ideais para o estabelecimento da sustentabilidade das formas de organização da produção nãoconvencionais, como no caso da produção socialista ou da produção autogestionária, convém discutir 
qual a situação real, apontada por alguns autores (GAIGER, 2002; TAUILE e outros, 2005), em relação à tecnologia adotada pelos empreendimentos autogestionários no Brasil a partir da década de 1990.

Ao apontar os resultados das pesquisas em empreendimentos autogestionários ligados às cadeias produtivas ou aos contratos de terceirização, Gaiger (2003) considera que estes empreendimentos tornam-se duplamente subordinados às condições de produção e comercialização impostas pelo capitalismo: por um lado, estão sujeitos às mesmas regras de comercialização estabelecidas ao conjunto de agentes econômicos, de conteúdo utilitário; por outro, como necessidade de responder ao aumento da competitividade e da produtividade, são compelidos a adotar a mesma base técnica utilizada pelas empresas convencionais, e os mesmos processos de produção introduzidos continuamente.

Quanto à solução proposta aos empreendimentos autogestionários para que estes mantenham suas características distintas da produção convencional, é necessário a estes empreendimentos "[...] assumir a base técnica do capitalismo, retirando benefícios para sua forma social de produção ou desenvolver forças produtivas específicas e apropriadas a essa forma social” (GAIGER, 2003, p.10).

Tais considerações são observadas, de forma empírica, na pesquisa realizada por Tauile e outros (2005) em um conjunto de 27 empreendimentos autogestionários em diversas regiões do Brasil, durante o ano de 2005.

Nesses empreendimentos os autores constataram, de forma geral, a adoção da base técnica herdada da empresa falida, com algumas modificações incrementais em máquinas e equipamentos, mas que na essência não constituem uma alteração nas características principais da base técnica herdada. Tais modificações foram consideradas pelos autores como "simples" adaptações técnicas em máquinas e equipamentos (alteração da velocidade de operação, substituição de peças secundárias, mudanças na configuração operacional, entre outras).

Apesar disso, os autores apontam que as situações encontradas, em termos da utilização da base técnica, são bastante diversas e específicas em relação ao setor produtivo em que está inserido ou à natureza do produto produzido pelo empreendimento. Nos setores em que existe um elevado grau de concorrência, os critérios para a manutenção dos empreendimentos no mercado são os de eficiência e produtividade estabelecidos pelas empresas que utilizam tecnologias atualizadas, e que dominam o mercado.

\section{Conclusão}

Os aspectos relacionados à viabilidade dos empreendimentos autogestionários e a realização de seus objetivos financeiros e sociais possuem como um dos principais elementos a tecnologia adotada no processo produtivo. Isso porque, no caso desses empreendimentos, não é suficiente que alcançam resultados financeiros positivos, mas tal resultado deve ser alcançado sob a manutenção dos princípios da autogestão da produção, como gestão democrática e participativa dos trabalhadores nos diversos aspectos da gestão, como a tecnologia adotada, metas de produção e de qualidade dos produtos, aplicação dos resultados financeiros, entre outros.

Assim sendo, os empreendimentos autogestionários, por atuarem no mercado e possuírem princípios e procedimentos que buscam o contraponto ao modelo de produção estabelecido pelo capitalismo, se deparam com um dilema: ou adotam a tecnologia convencional, adotada pelas empresas convencionais que objetivam a maximização do lucro e a especialização do trabalhador em funções específicas, ou a adoção de um modelo tecnológico apropriado às condições e objetivos da produção coletiva, como a igualdade na execução das funções por meio da rotatividade operacional.

No entanto a adoção de determinada tecnologia traz em si algumas implicações. No caso dos empreendimentos auutogestionário a adoção de um modelo tecnológico específico pode resultar em ganhos de curto prazo, porém comprometer a competividade do empreendimento, e por outro lado, permitir a manutenção no longo prazo, comprometendo, porém a implementação dos objetivos e princípios da produção coletiva.

Em razão dessas reflexões consideramos, por conseguinte, que a escolha de um determinado padrão tecnológico pelos empreendimentos autogestionários deve considerar aspectos que vão além da questão financeira, mas sim outros aspectos subjetivos considerados importantes para os trabalhadores associados, e que podem ser estabelecidos de forma coletiva e democrática pelos mesmos.

\section{Referências}

DAGNINO, R. P. Tecnologia social: uma estratégia para o desenvolvimento. Rio de Janeiro: Fundação Banco do Brasil, 2004. 
DAGNINO, R. P. Neutralidade da ciência e determinismo tecnológico. Campinas: Editora da Unicamp, 2008.

DRUCKER, P. F. Tecnologia, gerência e sociedade. Petrópolis: Vozes, 1973,

FARIA, M. S. Autogestão, cooperativa, economia solidária: avatares do trabalho e do capital. Florianópolis, UFSC (Tese de doutorado), 2003;

FEENBERG, A. Transforming technology. Oxford: Oxford University Press, 2002.

GAIGER, L. I. Eficiência sistêmica, in CATTANI, D. A. A outra Economia. Porto Alegre: Editora Veraz, 2003.

GARCIA, A. T. e VIÉITEZ, J. C. El desafio del cambio tecnológico: hacia una nueva organizacion del trabajo. Madrid: Tecnos, 1998.

GUILLERM, A., BOURDET, Y. Autogestão: uma mudança radical. Rio de Janeiro: Zahar Editores, 1976.

LADRIÈRE, J. Os desafios da racionalidade: $O$ desafio da ciência e da tecnologia às culturas. Petrópolis: Editora Vozes, 1979.

LIBONI, M. T. L. e PEREIRA, M. C. S. Entre contradições e inovações: a pesquisa de uma empresa de autogestão: o risco da naturalização da realidade. In: Encontro Nacional de Pesquisa e Pós Graduação em Administração (ANPAD). Bahia, 2002;

ROSANVALON, P. L'âge de l'autogestion. Paris: Éditions du Seuil, 1976.

SCHUMACHER, E. F. O negócio é ser pequeno: um estudo de economia que leva em conta as pessoas. Rio de Janeiro: Zahar, 1983.

SINGER, P. Introdução à Economia Solidária. São Paulo: Editora Perseu Abramo, 2002;

TAUILE, J. R. et al. Referências conceituais para ações integradas: uma tipologia da autogestão: cooperativas e empreeendimentos de produção industrial autogestionários provenientes de massas falidas ou em estado pré-falimentar. Brasília: SENAES/MTE, 2005.

VIEIRA PINTO, A. O Conceito de Tecnologia. Rio de Janeiro: Contraponto, 2005. 